\title{
STUDY OF SEMINAL MDA LEVEL AS A OXIDATIVE STRESS MARKER IN INFERTILE MALE
}

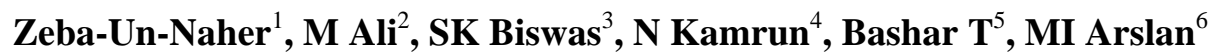

\begin{abstract}
Male infertility is an important medical and psychosocial problem worldwide. However, the underlying mechanism is far from clear in many cases of male infertility. Apart from known factors, it is therefore very important to identify new and non-conventional factors that may play significant role in male infertility. Oxidative stress has recently been identified as an underlying mechanism of numerous chronic diseases. Some studies have already claimed a relationship between oxidative stress and male infertility. The aim of the present study was therefore to evaluate whether there is an association between oxidative stress and male infertility in Bangladeshi subjects. MDA, the marker of lipid peroxidation was measured in the seminal fluid of fertile and age-matched otherwise healthy infertile male subjects. The sperm count, sperm morphology and motility, as well as semen volume were all found significantly lower in infertile subjects compared with fertile subjects. Interestingly, lipid peroxidation was found elevated seminal fluid of infertile subjects. The MDA was measured by thiobarbituric acid method. In seminal plasma, the median (range) MDA level was found significantly higher in infertile group (3.17 (1.20-6.21) versus $1.88(0.50-5.37) \mathrm{nmol} / \mathrm{ml}, \mathrm{p}<0.001)$.
\end{abstract}

Keywords: MDA, oxidative stress and infertile male.

\section{INTRODUCTION}

Infertility is a medical and social problem all over the world. Although infertility results from abnormality of the male partners in almost $50 \%$ of cases, it is a common prejudice to consider infertility as a problem of female partners. The underlying pathological basis of qualitative and quantitative defects of sperm leading to defects in fertilization is not clear in many cases. Since oxidative stress is involved with many chronic pathological conditions, the current study was designed to evaluate nay association that may exist between male infertility and oxidative stress. Infertility is a major clinical problem, affecting people medically and psychosocially. Infertility is defined as the failure of conception after at least 12 months of unprotected intercourse. ${ }^{1}$ In the United States, around $15 \%$ of all couples suffer from infertility. ${ }^{2}$ In India, it has been reported that one in every six couples suffers from infertility. ${ }^{3}$ Unfortunately, such data is not available for the people of Bangladesh. In many cases, the infertile couples appear healthy, but most of them suffer from serious psychosocial problems including marital disharmony, divorce and multiple marriage. Although the male partner is responsible for the infertility in about $50 \%$ of cases $^{3}$, women are often blamed for infertility in societies where there is a lack of education specially science education and male dominance prevail.

\footnotetext{
Medical Officer, Department of Ophthalmology, BSMMU, Dhaka Bangladesh.

Medical Officer, Department of Ophthalmology, BSMMU, Dhaka

Assistant Professor, Department of Biochemistry, BSMMU, Dhaka..

Consultant, Biochemistry, Department of Burn Unit, Dhaka Medical College, Dhaka..

Research Assistant, Department of Pharmacology, BSMMU, Dhaka.
} 
There are numerous factors that can affect the fertility of a couple. However, the factors that are responsible for male infertility have been conveniently classified into pre-testicular, testicular and post-testicular. ${ }^{4,5}$ The pre-testicular factors are related with hormonal imbalance and poor general health, and the important pre-testicular causes are hypogonadism, drugs, alcohol, smoking, ${ }^{6,7}$ psychological stress, genetic abnormalities, chemotherapy and different types of medications such as anabolic steroids, cimetidine, spironolactone, phenytoin, sulfasalazine and nitrofurantoin. The testicular factors, on the other hand, refer to conditions where the testes produce semen of low quantity and/or poor quality despite adequate hormonal support. The testicular causes of male infertility include age, chromosomal abnormality, seminoma, idiopathic oligospermia, varicocele, hydrocele and mumps. ${ }^{8}$ The post-testicular factors decrease male fertility by affecting the male genital system after testicular sperm production, and include defects of the genital tract as well as problems in ejaculation. Some important post-testicular factors are obstruction or absence of vas deferens, prostatitis, antisperm antibodies, retrograde ejaculation, ejaculatory duct obstruction, hypospadias and impotence. However, in many cases, the identification of the exact factor responsible for male infertility is quite difficult, and the mechanisms of the underlying defects of poor semen quality remain obscure. Therefore, potential non-conventional factors for the pathogenesis of male infertility have been sought, and recent studies suggested that oxidative stress might have profound role in male infertility. ${ }^{9}$ Oxidative stress is conventionally defined as an imbalance between pro-oxidant stress and antioxidant defense. The term pro-oxidant is not well defined; it is generally considered that a pro-oxidant is any substance that can generate reactive species or capable of inducing oxidative stress. A free radical is any species that contains one or more unpaired electrons, that is, electrons singly occupying an atomic or molecular orbital. ${ }^{10}$ Because electrons are more stable when paired together in orbitals, free radicals are generally reactive with other species. ${ }^{11}$ A reactive species may be a free radical or a non-radical in structure. There are three different classes of reactive species relevant in biology and medicine: a. reactive oxygen species (ROS), b. reactive nitrogen species, and c. reactive chlorine species. ${ }^{10}$

Consequences of oxidative stress can be very subtle to very serious (including oxidative damage to biomolecules, disruption of signal transduction, mutation and cell death) depending upon the balance between reactive species generation and the antioxidant defense. ${ }^{10}$ Reactive species can damage the living cells at different levels such as cell membrane, cellular proteins, lipids and DNA leading to a number of pathological consequences. The excess of ROS can be injurious to sperm survival and function when present in abundance. ${ }^{12,13,14}$ Lipids are present in sperm plasma membrane in the form of polyunsaturated fatty acids (PUFA). Most of the membrane PUFA contain double bonds that are separated by methylene groups. The presence of a double bond adjacent to a methylene group makes the methylene carbon-hydrogen bond weaker, and as a result the hydrogen is more susceptible to abstraction. Thus the lipids of sperm membrane are considered to be highly susceptible to oxidative damage. $^{12,13}$

One of the byproducts of lipid peroxidation is malondialdehyde (MDA). This byproduct is an important marker for oxidative stress, and it has been extensively studied to monitor the degree of lipid peroxidation. The peroxidation of the lipids in sperm membrane may cause changes in sperm, and may diminish fertility by affecting sperm motility and the capacity for sperm-oocyte fusion. However, it remains to be determined whether the seminal fluid MDA concentration affects sperm quality or function. ${ }^{15,16}$ 


\section{METHODS}

This case control study was done in the Department of Biochemistry, Bangabandhu Sheikh Mujib Medical University (BSMMU), Dhaka, Bangladesh. 31 diagnosed infertile male patients (having normal female partner) who attended in the infertility unit of Gynaecology and Obstetrics Department at BSMMU and 30 age-matched fertile healthy control subjects were taken purposively and conveniently by following the inclusion criteria and exclusion criteria:

Inclusion Criteria: Male partner of couples visiting the infertility unit of BSMMU have been studied for their suitability for this study as case whose female partner were found normal interim of fertility parameters. For selecting control group age matched fertile male having siblings were taken.

Exclusion Criteria: a) Those male subjects having one or more of the following criteria were excluded from this study:

- Acute illness within the last 3 months.

- Chornic illness like- neoplasm, e.g. seminoma; cryptorchidism; varicocele; trauma; hydrocele; mumps; malaria; testicular dysgenesis syndrome.

- History of genital tract infections (e.g. urethritis, orchtic etc.) and trauma (e.g. horse riding, cycling etc.).

- Persons under drugs for infertility (or other illness) that may affect sperm count within the last 3 months.

- Hypogonadism- hypogonadic subjects were excluded by testing serum testosterone, FSH, LH and prolactin. Estimation of serum testosterone, FSH, LH, prolactin and TSH were done by Microparticle Enzyme Immunoassay method. ${ }^{17,18,19}$

- Obstruction of vas deferens

- Hypospadias

- Retrograde ejaculation.

b) In excluding male patients as case, the female partners were studied for their fertility potential. Those male subjects were excluded from this study whose female partners had abnormal fertility parameters:

- Hormonal and ovarian factors - thyroid disorder, obesity, polycystic ovarian syndrome, androgen excess, hyperprolactinemia, hypothalamic and pituitary insufficiency.

- Tubal factor - occlusion or scarring of the fallopian tube and salpingitis.

- Cervical factors - stenosis, inflammation or infection and abnormal mucus viscosity.

- Uterine factors - leiomyomata, congenital malformation.

Laboratory method: Five $\mathrm{ml}$ of venous blood were collected. $2.5 \mathrm{ml}$ of blood was taken in a heparinzed test-tube for the assay of oxidative stress markers and from the remaining $2.5 \mathrm{ml}$ of blood, serum was separated by centrifugation for hormone analysis. Semen samples were collected from the subjects after 3-4 days of sexual abstinence. Samples were collected in the clinical facility by masturbation into a sterile glass container. ${ }^{9}$ For internal quality control of semen analysis, spermiograms were carried out by the trained observer, according to the World Health Organization guidelines. ${ }^{20}$ Spermiograms included semen volume $(\mathrm{ml})$, sperm density $\left(\times 10^{6}\right.$ per ml), sperm motility (\%) and abnormal morphologic features (\%). Semen samples were centrifuged and then seminal plasma was separated for determination of MDA concentrations.

Following parameters were analyzed in all study subjects- 
- Estimation of serum TSH, LH, FSH, Prolactin and Testosterone level

- Semen analysis

- MDA level of seminal plasma.

\section{Analytic methods:}

- Semen MDA level was measured by Thiobarbituric acid method. ${ }^{21}$

- Serum TSH done by Microparticle Enzyme Immunoassay Method (Abbott-AxSym). ${ }^{22}$

- Serum LH done by Microparticle Enzyme Immunoassay Method (Abbott-AxSym). ${ }^{23}$

- Serum FSH done by Microparticle Enzyme Immunoassay Method (Abbott-AxSym). ${ }^{24}$

- Serum Prolactin done by Microparticle Enzyme Immunoassay Method (Abbott-AxSym). ${ }^{25}$

- Serum Testosterone done by Microparticle Enzyme Immunoassay Method (Abbott-AxSym). ${ }^{26}$

Statistical Analysis: All the data were recorded systematically in a preformed data collection sheet. Data were analyzed by using SPSS 12.0 for Windows. Mann-Whitney U test and unpaired t-test were done to find significant difference between groups. Statistical significance was set at $\mathrm{p}<0.05$.

\section{Results:}

The present study was conducted in the Department of Biochemistry, Bangabandhu Sheikh Mujib Medical University from January 2008 to December 2009. During this period 31 infertile and 30 fertile male subjects were enrolled as case and control, respectively. The mean ages of case and control groups were $34.48 \pm 4.59$ and $35.83 \pm 4.46$ years, respectively (Table-I). As shown in Table-I, there was no statistically significant difference of age between case and control groups.

Table-I: Age distribution of the study subjects.

\begin{tabular}{|l|c|l|c|}
\hline Groups & $\begin{array}{c}\text { Total } \\
\text { Number }\end{array}$ & $\begin{array}{l}\text { Age (years) } \\
\text { (mean } \pm \text { SD) }\end{array}$ & p value \\
\cline { 1 - 3 } Case (Infertile Male) & 31 & $\begin{array}{l}34.48 \pm 4.59 \\
(27-45)\end{array}$ & 0.25 \\
\cline { 1 - 3 } Control (Fertile Male) & 30 & $\begin{array}{l}35.83 \pm 4.46 \\
(28-45)\end{array}$ \\
\hline
\end{tabular}

Data are presented as mean \pm SD. Unpaired t-test was done as the test of significance.

The semen analysis of the case and control was done for sperm count, sperm motility and sperm morphology. In addition semen volume also evaluated.

As shown in Table-II, sperm count was found significantly lower $(\mathrm{p}=0.001)$ in infertile males compared with healthy fertile male subjects here, Mann-Whitney $U$ value done for non parametric distribution of sperm concentration.

In Table-III ' $\mathrm{Z}$ ' proportion test shows significant $(\mathrm{p}=0.001)$ difference in sperm motility between case and control groups.

' $\mathrm{Z}$ ' proportion test shows significant $(\mathrm{p}=0.004)$ difference in sperm morphology between case and control groups (Table-IV).

In addition, semen volume was also found in Table-V lower in infertile subjects compared with fertile male subjects ( $2.34 \pm 0.96 \mathrm{ml}$ versus $3.26 \pm 0.73 \mathrm{ml}$, case and control, respectively; $\mathrm{p}<0.001)$. 
Table-II: Distribution of sperm concentration in case and control groups.

\begin{tabular}{|l|l|c|}
\hline Study subjects & $\begin{array}{l}\text { Median }\left(\mathbf{1 0}^{\mathbf{6}} / \mathbf{m l}\right) \\
\text { (Range) }\end{array}$ & p value \\
\hline Case & 19.00 & \\
$(\mathrm{n}=31)$ & $(5.0-150.0)$ & $<0.001$ \\
\hline Control & 100.00 & \\
$(\mathrm{n}=30)$ & $(25.0-180.0)$ & \\
\hline
\end{tabular}

Mann-Whitney test was done to measure the level of significance.

Table-III: Distribution of sperm motility by groups.

\begin{tabular}{|l|l|l|l|l|c|}
\hline \multirow{3}{*}{ Motility } & \multicolumn{2}{|c|}{$\begin{array}{c}\text { Case } \\
\text { (n-31) }\end{array}$} & \multicolumn{2}{c|}{$\begin{array}{c}\text { Control } \\
\text { (n-30) }\end{array}$} & \multirow{2}{*}{ p value* } \\
\cline { 2 - 5 } & No. & \% & No. & \% & \\
\hline Normal & 14 & 45.2 & 28 & 93.3 & \multirow{2}{*}{0.001} \\
\hline Abnormal & 17 & 54.8 & 2 & 6.7 & \\
\hline
\end{tabular}

*'Z' proportion test was done to measure the level of significance.

Table-IV: Distribution of sperm morphology by groups.

\begin{tabular}{|l|l|l|l|l|c|}
\hline \multirow{2}{*}{ Morphology } & \multicolumn{2}{|c|}{$\begin{array}{c}\text { Case } \\
\text { (n-31) }\end{array}$} & \multicolumn{2}{c|}{$\begin{array}{c}\text { Control } \\
\text { (n-30) }\end{array}$} & \multirow{2}{*}{ p value* } \\
\cline { 2 - 5 } & No. & \% & No. & \% & \\
\hline Normal & 21 & 67.7 & 29 & 96.7 & \multirow{2}{*}{0.004} \\
\hline Abnormal & 10 & 32.3 & 1 & 3.3 & \\
\hline
\end{tabular}

*'Z' proportion test was done to measure the level of significance.

Table-V: Distribution of semen volume in case and control groups.

\begin{tabular}{|l|l|l|c|}
\hline Study subjects & $\begin{array}{l}\text { Total } \\
\text { Number }\end{array}$ & $\begin{array}{l}\text { Volume (ml) } \\
\text { mean } \pm \text { SD }\end{array}$ & p value \\
\hline Case & 31 & $2.36 \pm 0.96$ & $<0.001$ \\
\hline Control & 30 & $3.26 \pm 0.73$ & \\
\hline
\end{tabular}

Data are presented as mean \pm SD. Unpaired t-test was done as the test of significance.

The blood samples of the case and control subjects were collected and the serum was used for hormone analysis. As shown in Table-VI, the concentration of serum testosterone $(5.66 \pm 2.32 \mathrm{ng} / \mathrm{ml}$ versus $5.20 \pm 1.76 \mathrm{ng} / \mathrm{ml}$, case and control, respectively; $\mathrm{p}=0.107)$, serum LH (5.43 $\pm 2.61 \mathrm{IU} / \mathrm{L}$ versus $5.33 \pm 2.46 \mathrm{IU} / \mathrm{L}$, case and control, respectively; $\mathrm{p}=0.602)$ and serum FSH $(5.42 \pm 1.70 \mathrm{IU} / \mathrm{L}$ versus $4.85 \pm 1.91 \mathrm{IU} / \mathrm{L}$, case and control, respectively; $\mathrm{p}=0.162$ ) were also found similar between infertile males (case) and healthy fertile male subjects (control).

Table-VI: Testosterone, LH \& FSH level in case and control groups.

\begin{tabular}{|l|l|l|l|}
\hline & $\begin{array}{l}\text { Case } \\
(\mathbf{m e a n} \pm \mathbf{S D})\end{array}$ & $\begin{array}{l}\text { Control } \\
(\mathbf{m e a n} \pm \mathbf{S D})\end{array}$ & p value \\
\hline Serum Testosterone $(\mathrm{ng} / \mathrm{ml})$ & $5.66 \pm 2.32$ & $5.20 \pm 1.76$ & 0.107 \\
\hline Serum LH (IU/L) & $5.43 \pm 2.61$ & $5.33 \pm 2.46$ & 0.602 \\
\hline Serum FSH (IU/L) & $5.42 \pm 1.70$ & $4.85 \pm 1.91$ & 0.162 \\
\hline
\end{tabular}

Data are presented as mean \pm SD. Unpaired t-test was done as the test of significance. 
Table-VII show the comparison of serum prolactin between case and control due to non parametric distribution of serum prolactin, Mann-Whitney $U$ test was done which, showed no significant difference $(\mathrm{p}=0.812)$ serum prolactin level.

Table-VII: Serum prolactin level in case and control groups.

\begin{tabular}{|l|l|l|}
\hline Study subjects & $\begin{array}{l}\text { Median (ng/ml) } \\
\text { (Range) }\end{array}$ & p value \\
\hline Case & 2.96 & \\
$(\mathrm{n}=31)$ & $(1.54-12.67)$ & 0.812 \\
\hline Control & 2.72 & \\
$(\mathrm{n}=30)$ & $(1.11-12.33)$ & \\
\hline
\end{tabular}

Mann-Whitney test was done to measure the level of significance.

To evaluate the oxidative stress to which the spermatozoa of the study subjects were exposed to, the levels of MDA in the seminal plasma were measured both in case and control groups. Median (range) MDA level of seminal plasma was found $3.17(1.20-6.21)$ and $1.88(0.50-5.37) \mathrm{nmol} / \mathrm{ml}$ in case and control groups, respectively. As shown in Table-X and Figure-3, the seminal plasma MDA level was found significantly $(p<0.001)$ elevated in infertile males compared with healthy fertile male subjects. (Table-X and Figure-4).

Table-X: $\quad$ MDA level of seminal plasma in case and control groups.

\begin{tabular}{|l|l|l|l|}
\hline Variable & $\begin{array}{l}\text { Case } \\
\mathbf{n = 3 1}\end{array}$ & $\begin{array}{l}\text { Control } \\
\mathbf{n = 3 0}\end{array}$ & p value \\
\hline $\begin{array}{l}\text { MDA Level of Seminal Plasma } \\
\text { (nmol/ml) (median-range) }\end{array}$ & $\begin{array}{l}3.17 \\
(1.20-6.21)\end{array}$ & $\begin{array}{l}1.88 \\
(0.50-5.37)\end{array}$ & $<0.001$ \\
\hline
\end{tabular}

Data are presented as median (range). Mann-Whitney U test was done as the test of significance.

The bar diagram shown in Figure-3 demonstrates the MDA level of seminal plasma from the case and control groups. The median (range) values of the MDA concentrations of seminal plasma and the statistical significance between case and control groups are shown in Table-X.

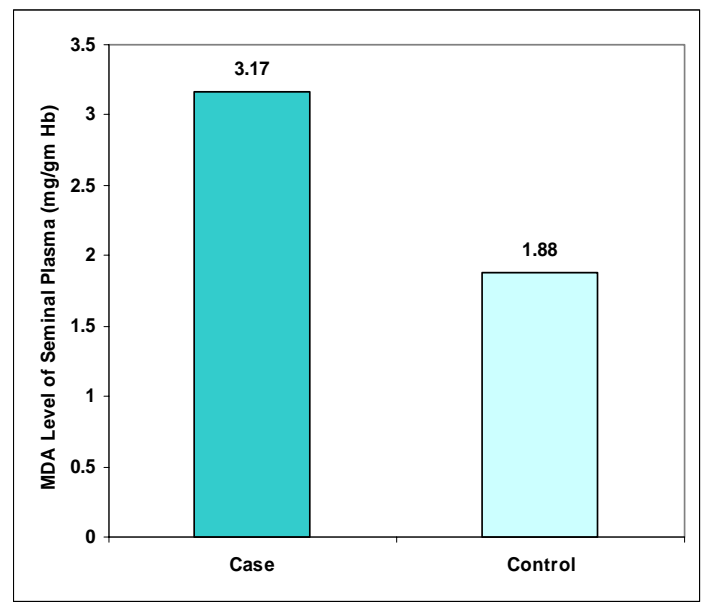

Figure-3: MDA level of seminal plasma in $\mathrm{nmol} / \mathrm{ml}$ in study subject. 


\section{DISCUSSION:}

Infertility is a common yet complex problem affecting approximately $15 \%$ of couples attempting to conceive a baby. Although infertility problems were attributed to the woman in the past, it is now known that male factors play a role in almost one half of cases. Male fertility depends on the production of normal sperm and the delivery of it to a female partner's reproductive tract. Most commonly, male infertility arises when the man is unable to produce or deliver fully functioning sperm. Numerous factors has already been identified that can lead to male infertility, however, the underlying mechanisms that cause qualitative and/or quantitative defect of the spermatozoa are still unclear in many cases of male infertility.

Oxidative stress has recently been linked with a number of chronic and inflammatory diseases. Free radicals within physiological concentration regulate sperm maturation, capacitation and hyperactivation, the acrosome reaction and sperm-oocyte fusion. ${ }^{2}$ However, oxidative stress resulting from excessive generation of reactive species compared with antioxidant defense capacity can cause lipid peroxidation, DNA damage and apoptosis of the sperm. ${ }^{27}$ The aim of the present study was therefore to evaluate the role of oxidative stress in the pathogenesis of male infertility. As a marker of oxidative stress-induced lipid peroxidation, seminal plasma MDA levels were measured in fertile and otherwise healthy infertile male subjects.

In the present study, MDA level was found markedly elevated in seminal plasma in infertile subjects compared with fertile control subjects. This finding suggests that the infertile subjects suffer from oxidative stress-induced lipid peroxidation. Several other studies also clearly showed an elevated MDA level in the seminal plasma of infertile and sub-fertile groups compared with healthy fertile group, ${ }^{15}$ which is actually similar to our present finding.

However, the finding of high level of MDA in the semen of infertile subjects clearly indicate that the spermatozoa of infertile subjects were exposed to increased oxidative stress. Moreover, the semen analysis report clearly showed both qualitative and quantitative defects of the sperm obtained from the infertile subjects. The sperm count, sperm morphology and motility, as well as semen volume were all found significantly lower in infertile subjects compared with fertile subjects. Thus it suggests that increased oxidative stress in the seminal fluid has a negative impact on semen quality. This is a very important finding, and it is well supported by several previously published studies. The semen analysis of the case and control was done for sperm count, sperm motility and sperm morphology. In addition semen volume also evaluated. This study showed sperm count was found significantly lower $(\mathrm{p}=0.001)$ in infertile males compared with healthy fertile male subjects, there is also significant $(p=0.001)$ difference in sperm motility between case and control groups and also significant $(p=0.004)$ difference in sperm morphology between case and control groups. A negative correlation has been shown between seminal fluid MDA level and sperm count, sperm motility and morphology. ${ }^{28,29}$ Taken together, it might be suggested that the oxidative stress was related with the abnormalities observed in the sperm morphology, count or motility in infertile subjects, and thereby the oxidative stress might have affected fertility of the male infertile subjects we studied in the present work.

Thus the findings of the present study although shows an association between oxidative stress and infertility, the obvious limitation of the present study is that it is unable to confirm that the oxidative stress was causally responsible for the infertility observed in the study subjects. Whether the oxidative stress itself inflicted any damage on the spermatozoa (such as peroxidation of membrane lipids, DNA modification or apoptosis) was not evaluated in the present study due to lack of technical support and funding. It would be interesting to study the oxidative stress-induced DNA base modifications as well as apoptosis of the spermatozoa obtained from infertile male subjects. Because, oxidative DNA 
damage in the sperm can affect fertilization and thereby can cause male infertility. ${ }^{27}$ Another limitation of the study is that oxidative stress of female partner was not evaluated. Thus further study with adequate sample size and extensive molecular experimental approach is recommended to reveal the role of oxidative stress in the pathogenesis of male infertility.

\section{REFERENCES}

1. $\quad$ Snick, HKA, Snick, TS, Evers, JLH \& Collins, JA 1997, 'The spontaneous pregnancy prognosis in untreated subfertile couples: the Walcheren primary care study’, Hum Reprod, vol. 12, pp. 1582-1588.

2. Makker, K, Agarwal, A \& Sharma, R 2009, ‘Oxidative stress \& male infertility’, Indian J Med Res, vol. 129, pp. 357-367.

3. Anjali, M 2010, 'Male infertility: preventing male infertility, male reproductive system', Retrieved 09.09.2010, <http://www.healthlibrary.com/afticle26. htm>

4. Cerilli, A, Kuang, W \& Rogers, D 2010, 'A practical approach to testicular biopsy interpretation for male infertility’, Arch Pathol Lab Med, vol. 134, pp. 1197-1204.

5. Bela, HG \& Pasquale, P 2010, Male fertility program, Yale Medical Group, viewed on 06.06.2010<http://www.yalemedicalgroup.org/YMG/directory/public/organization.asp? ID=109735 06.06.2010>

6. Seshagiri, PB 2001, 'Molecular insights into the causes of male infertility', J Biosci, vol. 26, pp. 429-435.

7. Zenzes, MT 2000, 'Smoking and reproduction: gene damage to human gametes and embryos', Hum Reprod, vol. 6, pp. 123-131.

8. Masarani, M, Wazait, H \& Dinneen, M 2006, 'Mumps Orchtitis', J R Soc Med, vol. 99, pp. 573575. viewed on $\quad 05.06 .2010<\mathrm{http} / /$ www.ncbi.nlm.nih.gov/pmc/articles/PMC16 33545/05.06.2010>

9. Khosrowbeygi, A \& Zarghami, N 2007, 'Levels of oxidative stress biomarkers in seminal plasma and their relationship with seminal parameters', BMC Clinical Pathology, vol. 7. retrieved on 04.08.2010 <http://www. biomedecntral.com/1472-6890/7/6>.

10. Halliwell, B \& Whiteman, M 2004, 'Measureing reactive species and oxidative damage in vivo and in cell culture: how should you do it and what do the results mean?', Brit J Pharmacol, vol. 142, pp. 231-255.

11. Halliwell, B 1989, 'Tell me about free radicals, doctor: a review', J Roy Soc Med, vol. 82, pp. 747-752.

12. Aitken, RJ, Gordon, E, Harkiss, D, Twigg, JP, Milne, P, Jennings, Z \& Irvine, DS 1998, 'Relative impact of oxidative stress on the functional competence and genomic integrity of human spermatozoa’, Bio Reprod, vol. 59, pp. 1037-1046.

13. Aitken, RJ \& Baker, MA 2004, 'Oxidative stress and male reproductive biology', Reproduction, Fertility and Development, vol. 16, pp. 581-588. viewed on 08.09.2010 <http://www.publish.csiro.au/paper/RD03089.htm.

14. Sikka, SC 2004, 'Role of oxidative stress and antioxidants in andrology and assisted reproductive technology', Journal of Andrology, vol. 25, pp. 5-18.

15. Chaudhari, AR, Piyali, D \& Ramji, S 2008, 'Study of oxidative stress and reduced glutathione levels in seminal plasma of human subjects with different fertility potential', Biomedical Research, vol. 19, pp. 207-210. 
16. Suleiman, SA, Ali, ME, Zaki, ZM, el-Malik, EM \& Nasr, MA 1996, 'Lipid peroxidation and human sperm motility: protective role of vitamin E', $J$ Androl, vol. 17, pp. 530-537.

17. Gronowski, AM and Landau-Levine, M 1999, 'Reproductive Endocrine Function', in Carl, AB, Edward, R \& Ashwood, WB (eds), Tiez text book of clinical chemistry, $3^{\text {rd }}$ Edition, Saunders Company, Philadelphia, pp. 1601-1636.

18. Demers, LA 1999, 'Pituitary Function', in Carl, AB, Edward, R \& Ashwood, WB (eds), Tiez text book of clinical chemistry, $3^{\text {rd }}$ Edition, Saunders Company, Philadelphia, pp. 1470-1492.

19. Newman, DJ \& Price, CP 1999, 'Thyroid function test', in Carl, AB, Edward, R \& Ashwood, WB (eds), Tiez text book of clinical chemistry, $3^{\text {rd }}$ Edition, Saunders Company, Philadelphia, pp. 1002-1010.

20. World Health Organization (WHO) 1992, 'WHO Laboratory Manual for the Examination of Human Semen and Sperm-Cervical Mucous Interaction', 3rd edn, New York: Cambridge University Press, pp. 1-20.

21. Rao, B, Souflir, C, Martin, M \& David, G 1989, 'Lipid peroxidation in human spermatozoa as related to midpiece abnormalities and motility’, Gamete Res, vol. 24, pp. 127-134.

22. Abbott Diagnostics, 'TSH estimation', Abbott Laboratories. Microparticle enzyme immunoassay. Abbott Park, Illinois, U.S.A. 2008.

23. Abbott Diagnostics, 'Luteinizing Hormone (LH) estimation', Abbott Laboratories. Microparticle enzyme immunoassay. Abbott Park, Illinois, U.S.A. 2008.

24. Abbott Diagnostics, 'Follicle Stimulating Hormone (FSH) estimation', Abbott Laboratories. Microparticle enzyme immunoassay. Abbott Park, Illinois, U.S.A. 2008.

25. Abbott Diagnostics, 'Prolactine estimation', Abbott Laboratories. Microparticle enzyme immunoassay. Abbott Park, Illinois, U.S.A. 2008.

26. Abbott Diagnostics, 'Testosterone estimation', Abbott Laboratories. Microparticle enzyme immunoassay. Abbott Park, Illinois, U.S.A. 2008.

27. Halliwell, B 2000, 'Why and how should we measure oxidative DNA damage in nutritional studies? How far have we come?', The American Journal of clinical Nutrition, vol. 72, pp. 1082-1087. viewed on 08.08.2010 <http://www.ajcn.org>

28. Yao-Yuan, H, Chi-Chen, C \& Chich-Sheng, L 2006, 'Seminal malonaldehyde concentration but not glutathione peroxidase activity is negatively correlated with seminal concentration \& motility’, Int J boil Sci, vol. 2, pp. 23-29.

29. Tavilani, H, Doosti, M \& Saeidi, H 2005, 'Malondialdehyde levels in sperm and seminal plasma of asthenozoospermic and its relationship with semen parameters', Clin Chim Acta, vol. 356, pp. 199-203. 